\title{
Encefalocele basal esfenoetmoidal associada a fissura labiopalatina mediana: relato de caso*
}

Basal sphenoethmoidal encephalocele in association with midline cleft lip and palate: case report

\author{
Maurus Marques de Almeida Holanda ${ }^{1}$, Artur Bastos Rocha ${ }^{2}$, Rayan Haquim Pinheiro Santos ${ }^{2}$, \\ Paulo Germano Cavalcanti Furtado ${ }^{3}$
}

\begin{abstract}
Resumo Associação de encefalocele basal esfenoetmoidal com fissura labiopalatina é extremamente rara. Relatamos um caso de uma criança de nove anos de idade apresentando uma fissura facial mediana com meningocele, que era evidente através da falha do palato como uma massa mediana intranasal pulsátil. Uma análise dos aspectos clínicos e radiológicos deste caso de disrafia craniana foi realizada.

Unitermos: Encefalocele; Fissura palatina; Malformação congênita.

Abstract Association of basal sphenoethmoidal encephalocele with midline cleft lip and palate is extremely rare. The authors report the case of a nine-year-old girl presenting a midline facial cleft with meningocele that was noticeable through the palatine defect as a medial intranasal pulsatile mass. An analysis of clinical and radiological findings of the present case of cranial dysraphism is carried out.
\end{abstract}

Keywords: Encephalocele; Cleft palate; Congenital malformation.

Holanda MMA, Rocha AB, Santos RHP, Furtado PGC. Encefalocele basal esfenoetmoidal associada a fissura labiopalatina mediana: relato de caso. Radiol Bras. 2011 Nov/Dez;44(6):399-400.

\section{INTRODUÇÃO}

Meningocele esfenoetmoidal é um defeito congênito da fossa craniana anterior com herniação de meninges e eventualmente partes do cérebro, encefalomeningocele, determinando uma protrusão para a cavidade nasal através de defeito no etmoide e esfenoide. É um subtipo da encefalomeningocele basal ${ }^{(\mathbf{1})}$.

Diversas são as classificações que têm sido propostas para as encefaloceles da fossa craniana anterior, que, de forma simplificada, são divididas de acordo com a topografia da herniação em dois grandes grupos. No primeiro grupo encontram-se as encefaloceles sincipitais (frontais) que se exteriorizam através do forame cecum por

* Trabalho realizado na Universidade Federal da Paraíba (UFPB), João Pessoa, PB, Brasil.

1. Doutor, Neurocirurgião, Professor Adjunto de Neurologia da Universidade Federal da Paraíba (UFPB), João Pessoa, PB, Brasil.

2. Acadêmicos de Medicina da Universidade Federal da Paraíba (UFPB), João Pessoa, PB, Brasil.

3. Professor Adjunto de Cirurgia Infantil do Departamento de Pediatria e Genética da Universidade Federal da Paraíba (UFPB), João Pessoa, PB, Brasil.

Endereço para correspondência: Dr. Maurus Marques de Almeida Holanda. Rua Borja Peregrino, 191, Torre. João Pessoa, PB, Brasil, 58040-050. E-mail: maurusholanda@hotmail.com

Recebido para publicação em 18/4/2011. Aceito, após revisão, em 31/5/2011. diante da placa cribriforme do etmoide. No segundo grupo incluem-se as encefaloceles basais que fazem protrusão através da própria placa cribriforme ou do corpo do esfenóide ${ }^{(2)}$.

A prevalência das encefaloceles em geral é estimada em 1 caso para cada 35.000 a 40.000 nascidos vivos. As formas basais, ainda mais raras, constituem apenas $2 \%$ a $10 \%$ dessas encefaloceles ${ }^{(\mathbf{3 , 4})}$. Como se trata de uma associação de malformações rara, de alta morbidade e mortalidade em seu tratamento, com poucos relatos na literatura, uma análise dos aspectos clínicos e radiológicos deste caso de disrafia craniana foi realizada.

\section{RELATO DO CASO}

Criança do sexo feminino, nove anos de idade, apresentando fissura labiopalatina mediana, hipertelorismo, baixo desenvolvimento pôndero-estatural e desenvolvimento intelectual normal. Ao exame da cavidade oral, uma fissura palatina ampla permitia a visão direta de tumoração cística pulsátil arredondada, de cor acastanhada, superfície lisa e regular, com cerca de $4 \mathrm{~cm}$ de diâmetro, localizada na linha média da cavidade nasal (Figura 1). Foi obtido con-

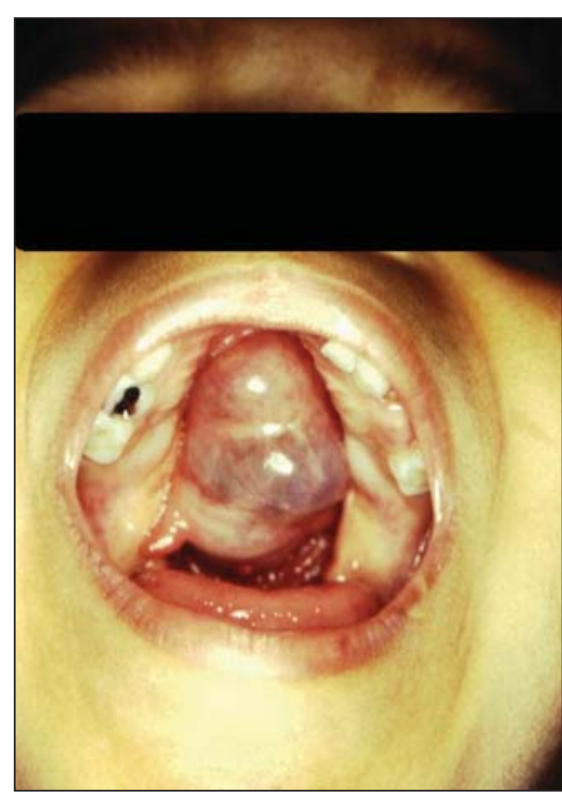

Figura 1. Encefalocele basal esfenoetmoidal. Vi sualização pela fissura palatina ampla da tumoração cística pulsátil.

sentimento livre e esclarecido da mãe da criança e liberação pelo conselho de ética para publicação.

A tomografia computadorizada (TC) demonstrou diástase da sutura metópica, caracterizando hipertelorismo, e uma sela turca vazia ocupada por imagem cística. A 


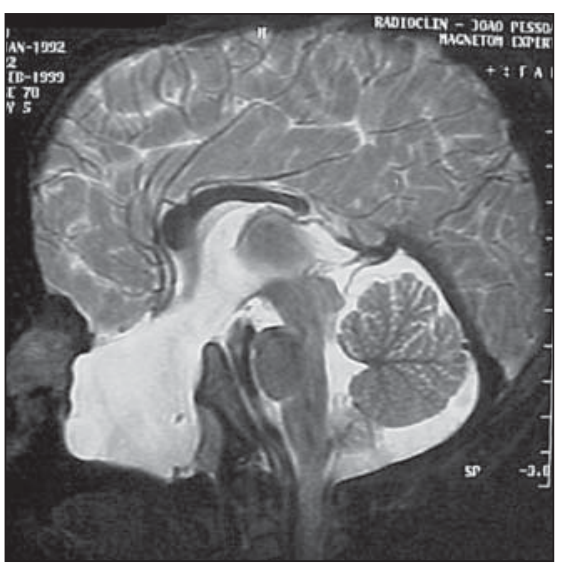

Figura 2. RM, corte sagital mostrando imagem com densidade de líquido na região anterior da base do crânio (T2).

ressonância magnética $(\mathrm{RM})$ demonstrou imagem com densidade de líquido na região anterior da base do crânio, mostrando falha etmoidal e esfenoidal na linha média com extensão nasal, e evidência também de falha no palato duro (Figuras 2 e 3 ).

A paciente apresentava idade cronológica de nove anos e óssea de cinco anos. Seu hormônio do crescimento $(\mathrm{HGH})$ basal após clonidina foi de $0,2 \mathrm{ng} / \mathrm{ml}$ (referência: 0 a $10 \mathrm{ng} / \mathrm{ml}$ ).

\section{DISCUSSÃO}

São escassos os dados na literatura nacional e estrangeira relatando a associação aqui apresentada.

Fatores geográficos e raciais influenciam tanto na frequência quanto na área do cérebro a ser comprometida, mostrando-se endêmicas no sul da Ásia. Em dois serviços em Bangkok, na Tailândia, apenas no período de 1992 a 1996, foram relatados 120 casos de encefalomeningocele frontoetmoidal (sincipital). A forma basal, porém, é rara em todos os grupos raciais ${ }^{(5)}$.

Clinicamente, as encefaloceles basais podem se manifestar como uma massa na linha média da cavidade nasal causando, ou não, obstrução, dificuldade de alimentação, vazamento de líquor e meningite. Podem associar-se a fissura labiopalatina, microftalmia, nariz bífido e coloboma do nervo óptico. Tratando-se de uma massa nasal, devem ser considerados no diagnóstico
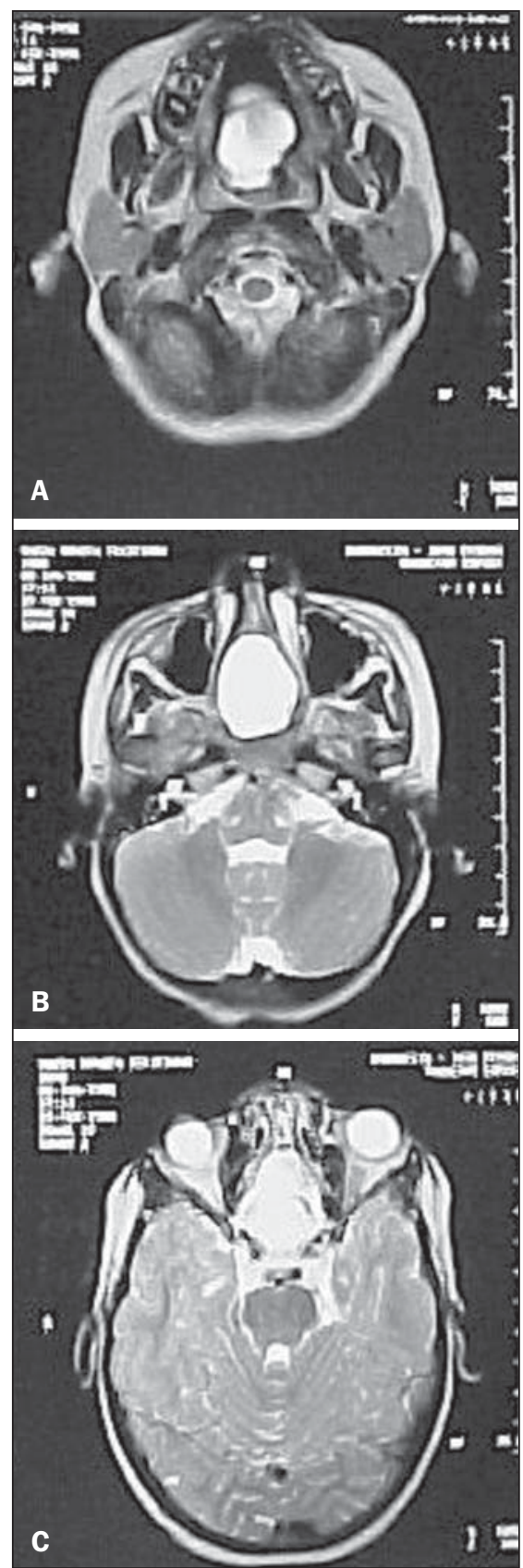

Figura 3. RM, corte axial mostrando a falha etmoi dal e esfenoidal na linha média com extensão nasal, com evidência de falha no palato duro (T2).

diferencial dos gliomas, cistos dermoides e pólipos ${ }^{(\mathbf{1})}$.

Estudos avançados de imagem são extremamente necessários, tanto para confirmar o diagnóstico quanto para analisar o conteúdo do saco herniário. É importante a realização de TC de crânio não contrastada com reconstrução tridimensional para avaliar o defeito na base do crânio e de RM para analisar os elementos do saco ${ }^{(4)}$.

A RM pré-operatória foi essencial por fornecer informações valiosas como a localização das estruturas vitais dentro do saco herniário. O saco herniário apresentava apenas líquor no seu interior, sem a presença de estruturas cerebrais, caracterizando rigorosamente uma meningocele basal. A sela turca vazia explica o quadro de insuficiência hipotálamo-hipofisária que pode estar presente em $60 \%$ dos $\operatorname{casos}^{(6)}$.

Além disso, atualmente a RM tem sido bastante empregada para o diagnóstico intraútero de anomalias do sistema nervoso central, sendo, nesse caso, um exame mais sensível do que a ultrassonografia ${ }^{(7,8)}$.

O prognóstico é reservado. Pouco mais da metade dos casos tratados apresenta evolução favorável. De um relato de 114 pacientes, $59 \%$ evoluíram normalmente, $18 \%$ apresentaram algum grau de deficiência física ou mental, e $23 \%$ são portadores de deficiência severa ${ }^{(2)}$.

Além da raridade do caso, devem ser ressaltados o elevado índice de morbidade, mortalidade e o risco das gravíssimas complicações, quando, confundindo o diagnóstico com cisto dermoide ou pólipo nasal, o cirurgião tenta de forma inadvertida proceder a sua extirpação.

\section{REFERÊNCIAS}

1. Hoving EW. Nasal encephaloceles. Childs Nerv Syst. 2000;16:702-6.

2. Macfarlane R, Rutka JT, Armstrong D, et al. Encephaloceles of the anterior cranial fossa Pediatr Neurosurg. 1995;23:148-58

3. Monteiro M, Albuquerque AC, Nobre MC, et al Meningoencefalocele transesfenoidal transpalatina. Arq Neuropsiquiatr. 2006;64:624-7.

4. Rathore YS, Sinha S, Mahapatra AK. Transsellar transsphenoidal encephalocele: a series of four cases. Neurol India. 2011;59:289-92.

5. Rocha LCM, Genes M. Disrafismo craniano encefaloceles. Prat Hosp. 1989;4:6-16.

6. Lees MM, Hodgkins P, Reardon W, et al. Frontonasal dysplasia with optic disc anomalies and othe midline craniofacial defects: a report of six cases. Clin Dysmorphol. 1998;7:157-62.

7. Peruzzi P, Corbitt RJ, Raffel C. Magnetic resonance imaging versus ultrasonography for the in utero evaluation of central nervous system anomalies. J Neurosurg Pediatr. 2010;6:340-5.

8. Rosen H, Chiou GJ, Stoler JM, et al. Magnetic resonance imaging for detection of brain abnormalities in fetuses with cleft lip and/or cleft palate. Cleft Palate Craniofac J. 2011;48:619-22. 